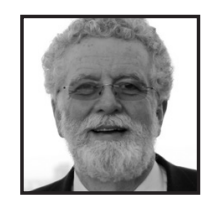

\title{
Commentary Building Bonds: Community and Education
}

Noel Burke

\begin{abstract}
In this interview, Noel Burke describes how his passion for linking community, education, and lifelong learning began early in his career as a teacher and continued throughout his various roles in educational settings. He gives examples of several projects in which he was involved, highlighting both successes and failures. He explains the key factors that promote successful community-education projects and concludes by giving advice to young professors about integrating their research interests in the community.
\end{abstract}

(1)) You have been a long-time advocate for initiatives that link education and community. Can you talk about when you realized this passion and what contributed to it?

guess I might go back to my own high school experience and a kind of disconnect I felt in high school with what we were learning and what I thought we should be learning, although I hadn't formulated those ideas yet. Although I didn't know where I wanted to be going, I knew this wasn't getting me there.

I started teaching very early and worked at James Lyng High School in St-Henri, which was a school very much imbedded in the community. Many students came from impoverished families and therefore brought their life into school, and not just the assignments they had to do. One of the first projects I got involved in was a career exploration project. I thought that students in that area were not sufficiently exposed 
to the opportunities that might be available to them, particularly in CEGEP. I started a project called CEGEP Preview, where we were exposing students who themselves or their families had not considered higher education. We talked to them about all the opportunities that were available to them in CEGEP studies, which were free, and the connections between the various programs at the CEGEP level and occupations. That was my first attempt at making the connection between school and adult life for students. Making high school relevant for students became a passion for me. I understood that to be relevant you had to connect with the community. That's what brought me to working over the years in adult education, in particular, and lifelong learning. I have always understood that learning has no beginning other than birth and no end other than death. I got very much involved in vocational education, adult education, extended learning at Concordia University, and a wide range of projects over a 40-plus year career, all of which looked at making education more accessible and relevant to individuals and the community.

This drive manifested itself completely in the creation of the Community Learning Centre project in which I thought we were filling in the other half of the picturewhich up to that point had been bringing individuals to educational settings to continue their education. The Community Learning Centre was an attempt to bring the community itself to the school-not just individuals-and come to an understanding that education was not defined by or even confined to the curriculum. In my undergraduate days at McGill they used to talk about the "overt" and "covert" curriculum. It turns out that the covert curriculum was the real curriculum. In a number of workshops I did with parents over the years, I would ask them: "What is it that you would expect a student to learn, what would be the skills you would want a student to have by the time they completed high school?" And I generated a list of about 20 skills through these repeated workshops and few of those 20 (and, in fact, maybe two or three out of 100 responses) would have anything to do with overt curriculum which is the textbooks and the government curriculum.

I got very heavily involved in the implementation of the QEP reform in the early 2000s, specifically because for the first time, in a government curriculum, the notion of lifelong learning and cross-curricular competencies came into play, namely the covert curriculum that had been in place for three quarters of my career had been mainstreamed. 
(1)) Can we talk about one or two of the projects in some detail that you've been involved in that were very interesting to you?

There are two that were most interesting to me: one was a success and one was a personal failure. I'Il talk about the failure first. I was appointed at Concordia University as the founding Dean of the School of Extended Learning. The idea behind this school was to manifest in a more concrete way the unspoken mission of Concordia University. Although everybody in the community knew it as a "people's university," that it was accessible, and that it didn't have, other than Loyola, that image of a campus "ivory tower" that people have, correctly or not, about McGill. It was to manifest that kind of accessibility to higher education for individuals and organizations. Although all of this happened in various departments and faculties, it wasn't a concrete movement. I wanted to create a vision around what a school that provides that kind of accessibility might look like. We went into an extensive vision-making process facilitated by expert facilitators. That took about a year and we created a mandate for the school that would include a preparatory program for underqualified students. There was, and is, a high first-year dropout rate, and once you lost someone in the first year, you lost those funding counts for the next three years. We started programs like a prep program for underqualified students as well as supporting a "University of the Streets" program that had been in place for some time, but that we brought into the mainstream and created an Office of Community Affairs in the vice-president's office, which didn't exist before.

Some of the successes of that project were building into the structure of the university some of the things that were just assumed, but were haphazard in their application. The success of the school in being able to manifest a wider accessibility to the university didn't work out because of territorial and structural issues within the university, departments, and faculties. It was an environment that at the time was all about keeping the numbers up and all of the budgets that were allocated to departments and faculties were based on student numbers. Someone like myself who comes along and says, "We're going to scoop up all these students and guarantee you that they are going to stay longer," was very attractive to the administration of the university, but very unattractive to the faculties and departments whose budgets relied on those students. So, it was a failed attempt in terms of what the intention was, but successful in inspiring, in a more concrete way, new kinds of community-university relationship. 
The most successful project is the Community Learning Centres. I'd have to say that this was the pinnacle of my career. We went on a mission to Europe in 2004 with a number of people from different school boards. We were looking at best practices for lifelong learning, to provide advice to the Ministry of Education on how we might improve and sustain a better lifelong learning policy on adult education. While we were there, I got excited about some initiatives, particularly in Sweden and in England. In Sweden, the "Folks Schools" are higher education settings in which any group of people, four or more, could actually approach the government for funding to learn whatever they wanted to learn. That was really exciting. In England, we witnessed a lot of examples of intergenerational learning where we saw illiterate adults learning to read with young children. It was a very emotional and beautiful experience to see that learning unfold. As well, vocational education recruitment programs which were storefronts in shopping malls where you could shop around if you were interested in this career or that vocation. You could sit down with somebody in a storefront and talk about how to move ahead and get a career and find a place that would train you for the career. All these things spoke volumes to a number of us around the table, about the question, "How do we connect community and school in a better way?" That led us to look at the community-school initiative that had started in Scotland in the late 1950s and then had later manifestations in the States.

All of this to say that when we came back we got a very attentive ear of the school boards. We sold community learning centres to the school boards, legitimately so, by saying that the English school demographics were against us over time and that many schools were closing or threatened with closing. Having a community centre would keep those schools afloat. I was the Assistant Deputy Minister of Education at the time, and I had to pitch the idea to the Minister. I pitched it by saying, "You're renting facilities all over the province to provide government services to citizens and yet here's a whole bunch of half-empty buildings that are threatened with closure because you have a building built for 300 students in which there are 75, 100 students. Wouldn't it be logical now to keep those buildings open, keep the schools in their local community, and offer government services in facilities that you don't have to pay rent for?" They loved that idea, but have yet to realize it. The real intention, though, was to get the community involved in schools.

We saw examples in England where the annual inoculation for the flu was given in schools and the transportation networks of busing kids to schools was also used for senior citizens and other people to come to the school during the daytime and have access to social services, health services, and learning and training in a variety 
of ways, really engaging the school in its mission to serve the community, rather than to serve only young people and to only hope that young people would make the connection with what their role is in the community; what their community means to them. By having these multigenerational and multi-educational programs going on in the school, it really started to become transparent and the community really, in those circumstances - to a lesser extent here-started to feel they owned the school, that it was their school. Even there, in those circumstances when we talked to people, they didn't even call it a school; they called it a learning centre. This was where the community learns and grows.

11)) What factors in your experience have to be in place for linking education and community and for making such initiatives successful? What's behind all that?

Off the top of my head, there are four things. One: a willingness and an openmindedness to explore alternative approaches to schooling and education. Two: the willingness of both parties to find a middle ground. The difficulties we had at the beginning of the program were territorial difficulties. Teachers wanted to know that the chalk and blackboard would be in the same place the next morning after people came into their classroom at night. Territorial issues with the school boards in terms of people being in the building, raising insurance issues, maintenance issues, and cost issues, which I think were artificial issues, like the perceived inhibition of community members to enter into schools. I think most of the resistance was within the school system, not within the community. So, a willingness to find middle ground.

The third condition would be the ability to listen to each other, to kids, to parents. In conversations that we got in, individually with people, all of those concerns were not there. The real concerns were of parents about unknown adults being in the building with children and adolescents, but conceptually there was never a problem with the project.

The fourth condition might be an openness at the administrative level both in schools and, more particularly, in school boards, to the notion of exploring and innovation. We talk a lot in education about innovation, but we don't really do a lot. A tremendous amount of innovation happens in the classroom and I would suggest that occurs despite the limitations of the current structures and the entitled power structure that exists within school boards-that's the real inhibitor. When we first introduced community learning centres to school boards, we went to the school board association and the chair of the association at the time said: "I don't see what you're 
getting at. People use our gyms every night, people come in and play basketball in the gyms, we're open to the community." Our thought on hearing that was it just went completely over their heads; they had no real conceptual notion of it. Perhaps that's the fourth condition: a real good acclimatization and preparation of people in power who can control whether those things really happen or not. If I go back to the European mission I think our mistake, and I've said it a number of times, was not taking the Directors General of the school boards with us.

We took the "converted parishioners" with us, the people we already knew would be inspired by the trip. We should have taken more administrators. That's who you need to get excited about it and to build their confidence around innovation.

It is really less a power struggle than it is a confidence to change. The comfort and confidence level around changing and taking risks is a condition that you need to be assured of to make it happen. And if there's an overriding condition, it would be to minimize people's perception of what the risks are in making those kinds of changes. Nobody said about CLCs, "That's a stupid idea; that's not going to work." To a person everybody said, "Yeah, that's really interesting and exciting."

11)) What challenges do educators and community partners face when embarking on collaborative endeavour? Let's say you've convinced them to do it, but now you want to operationalize it. What are the next hurdles or challenges that occur?

Principal among them is shared resources. How do we share the resources, who owns what, will what I have be compromised by it, so shared space, shared time-those were and are the real challenges. Overall, if we take a helicopter view, it's really about the change process. All these issues that are brought up, shared space, shared time, shared resources, where's the money, who owns what, I think these are masks for the real challenge and the risks people take in the change process. I used to think that fear of change was about where you're going-and a lot of the projects and initiatives I worked on have not met their objectives because we thought, and I thought, that that's what you have to convince people of-this is an exciting place to go to. Conceptually, people can buy into that, but practically, they don't because, I have realized over time, that people's fear of change is not about where they are going, but what they are leaving behind.

There's a comfort level, security, and confidence provided by the status quo, even if it's dysfunctional. Even if a teacher says, "The way they organize high school 
or the way evaluation is done is phony or artificial or not sufficient really to determine student success," they're tied to it because it's there. There's a comfort level about it both in that it's a familiar ground and also because it's somebody else who's imposing it on them. It's really about being able to allow people to bring what makes them comfortable and confident forward into a new experience or a new environment. That was the challenge of the reform; and I have to say that we were not successful in that, even in the community learning centre project. I wouldn't say that was the success of the project, because I don't think, even now, (and I haven't been in any of them in five or six years) they are still, to use an overused term, "two solitudes." The teacher in the classroom and the community activities-many still occur after school, in the evenings, on the weekends. Generally speaking, there's not yet a synergy there that would have been expected and that we witnessed in the European schools that we visited. There was clear synergy there, but if there is a next stage in the development of the community learning centres it is the challenge of creating synergy around educational and community services, rather than just having more activities happening in school.

1)) What recommendations do you have for young professors who wish to get involved in community-based work that will be relevant to their careers in their educational posts?

As with any academic, they have to have both a personal sense of mission and do practical research. Get out to a school and talk to students and teachers. In an education faculty, in particular, to be able to generate tools that teachers can use in their practice is important. Any time that occurs there is absolute positive traction. Teachers are faced with extraordinary circumstances and challenges on a daily basis and because they're expected to be psychologists, social workers, parents, teachers, fire fighters, nurses, all simultaneously and on demand, their need as a profession is to have an extensive toolkit. Wherever academics can bring value-added to the practice, whether it's by tools or experience or research, that's powerful. Also, engaging teachers themselves as researchers and valuing their capacity to observe, to record, to witness the experiences that they're having, I think is very powerful too.

Young academics who are looking for tenure, or early in tenure, but more particularly those seeking tenure (which is probably more than there used to be) are inhibited by structures and organizations. If somebody says, "You can't do research here," they just turn and go somewhere else. Much like in the community learning centres, there's a need for a dialogue at the administrative level because the system is unfortunately still very hierarchical, both in universities and school boards. There needs to be a dialogue at the top end that opens these doors for mutually 
beneficial activities to go on, whether it's research or community-based learning, or community learning centres. Overall, in all the questions you've asked, I think the problem is upstairs, in the administration of the organization; not downstairs in the classroom. I shouldn't say "downstairs" in the classroom-in the new world order the classroom will be at the top of the pyramid! The lack of dialogue that's going on between those levels continues to inhibit engagement, growth, and innovation.

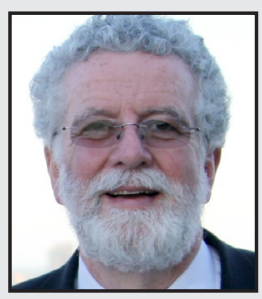

Noel Burke is the founder and principal partner of nEDworks Consulting, providing consultation services to educational stakeholders as well as leadership and career coaching to individuals and organizations. He combines a rich background in management, leadership, and teaching, most recently as the Founding Dean of the School of Extended Learning at Concordia University. Noel previously served as the Assistant Deputy Minister of Education of Quebec for the English-speaking community. He has had and continues to have an influential role in numerous other educational initiatives throughout the province. Noel holds a BEd and MEd (in Administration and Policy Studies) from McGill University, and the Professional and Personal Coaching Certification (PPCC) from the International Coaching Federation (IFC). 